\title{
Analysis on the Predicament of Destination Brand Personality Creation from the Perspective of New Media
}

\author{
Wanxin $\mathrm{Shi}^{1, *}$ \\ ${ }^{1}$ School of Tourism Management, Tianjin Vocational Institute, Tianjin, China \\ *Corresponding author. Email: shiwanhsin@163.com
}

\begin{abstract}
The booming mobile Internet technology in the new era poses opportunities and challenges to destination marketing. In view of the severe homogenization of products and the changing needs of tourists, branding has become an important means of destination marketing. This paper introduces the concept of "brand personality" and analyzes the development status and significance of destination brand personality from the perspective of new media. However, there still exist the following problems in shaping destination brand personality: the neglect of the value of brand personality, the lack of integration of destination resources; underutilized new media platforms in destination marketing; tourism brand marketing that does not meet the demands of tourists; and unclear destination brand evaluation index and evaluation mechanism. Corresponding management recommendations were also proposed in this paper.
\end{abstract}

Keywords: new media, brand personality, tourism destination

\section{INTRODUCTION}

The booming mobile Internet in the new era begets various media circulating information. The dramatic development of more three-dimensional, interactive and autonomous we-media platforms further defines the relationship between product producers and consumers. Destination managers dominate traditional tourism destination marketing, integrate local resources, and deliver product information to tourists. However, highly homogeneous tourism destination products cause perceptual fatigue. The upgrading of tourists' demands makes them pay more attention to the emotional value, life taste and identity characteristics of products in tourism destination than functional attributes. Destination resources that are easy to be imitated are no longer the most attractive appeal for tourists. The unique cultural genes and core values of tourism destinations serve as the key to win the fierce competition among tourism destinations. Tourism destination brand has become powerful support to cope with external environmental challenges, realize reform, transformation and upgrading, and highlight the competitive advantages of destinations.

The catalysis of new media makes tourists change from simple product buyers and information receivers into information producers and communicators with

*Fund: This paper is a project supported by the Scientific Research Fund of Tianjin Vocational Institute: A Comparative Study of Brand Projected Personality and Brand Perceived Personality of Tianjin Cultural Tourism Brand. (Subject No.:20192104) multiple identities. Compared with official propaganda, tourists' personal experience is more convincing and oriented for potential tourists, thus challenging traditional tourism destination marketing. With the increasing say and dominance of tourists in destination products and information [1], understanding tourists' perception and listening to tourists' feedback are important steps to construct products and services that meet tourists' needs. It is imperative to find the breakthrough point of tourism destination marketing.

Brand personality reflects the personality of the brand, values the unique connotation of the brand, becoming the breakthrough point in the process of destination branding. This paper introduces the concept of "brand personality", tries to analyze the problems and difficulties encountered in creating tourism destination brand personality in the context of new media, and provides insights for destination brand marketing.

\section{RESEARCH STATUS OF DESTINATION BRAND PERSONALITY}

As the key to end product homogeneity, brand personality has been widely concerned, and its connotation and denotation have been constantly expanded. Meanwhile, the concept of brand personality is introduced into destination brand marketing, excavating and refining the core genes that distinguish itself from other destinations, as well as finding 
emotional and cultural elements that meet the needs of tourists.

\section{A. The concept of destination brand personality}

American scholar Aaker (1997) defined brand personality as "a series of personality characteristics related to certain brand" based on the theoretical model of "Five Personality" in psychology. [2] Such concept has been widely recognized by existing researches and widely cited and applied in researches on brand construction. Upushaw (1999) holds that brand personality is the emotional bond connecting physical products and consumer groups. [3] Zhang Chunhui and Bai Kai (2011) take that compared with the functional attributes, brand personality carries the culture, emotion, value and other symbolic meanings of the product. Most consumers choose brands with brand personality traits similar or complementary to their own emotional demands [4]. Brand personality gives the product "human personality" and personifies the product to increase its recognition and competitiveness.

The research of tourism destination brand personality appears relatively late. Henderson (2000) introduced brand personality into tourism destination research and studied the role of brand personality with Singapore as a case [5]. Ekinci and Hosany (2006) introduced the concept of brand personality into destination brand management, believing that destination brand personality refers to personality characteristics recognized by tourists and associated with the destination [6].

In general, most of the existing studies follow the concept of brand personality proposed by Aaker and apply it to destination brand management. The concept of tourism destination brand personality mainly includes three aspects: first, destination brand personality endows destination with personification; second, the brand personality strengthens the emotional connection between the destination and tourists, which satisfies individual needs of tourists; third, the brand personality improves destination recognition, enhances uniqueness and improves competitiveness.

\section{B. The significance of creating destination brand personality}

1) Promoting destination differentiation from homogeneous resources: The booming tourism caused homogenization problems, including similar tourism resource development concepts, nearly identical tourism project planning and single tourism marketing methods, severer. Allowing tourists feel the difference and uniqueness between brands is critical to make tourism destinations stand out, which is conducive to prolonging the life cycle of destinations, improving their competitiveness and achieving long-term sustainable development. Therefore, it is urgent to explore the resource and personality of tourism destination, looking for knock-out products, thus building bridge between consumers and the destination.

The destination brand personality reflects the uniqueness of destination resources and vividly reveals the cultural and spiritual value here. The construction and refinement of destination brand personality can further promote the optimization of tourism resources, the refinement of local characteristics, and the exploration of cultural core.

2) Promoting positive feedback and loyalty of tourists: Research on the relationship between destination brand personality and tourist behavior shows that destination brand personality is positively correlated with travel motivation, willingness to revisit, recommendation and tourist loyalty. The participation of various stakeholders of the tourism destination challenges the decision-making power of destination managers, who are the dominant players in tourism marketing [1]. Various interactive media platforms accompanied with mobile Internet have gradually enhanced the discourse power of tourists, making them important participants in determining the destination image and brand communication. In the process of destination brand creation, tourists will independently construct brand content based on tourism experience, cultural background and other factors, and develop loyalty and attachment to destination that has brand personality that fits their personality.

\section{Dimensions of destination brand personality}

The existing researches usually employ qualitative or quantitative methods combined with case analysis to measure and study the dimensions of different destinations.

As for research content, many scholars adopt or improve the brand personality measurement system proposed by Aaker to study the brand personality characteristics of different countries. Among them, Huang Shengbing and Lu Taihong (2003) expounded the personality dimensions of Chinese brands from the perspective of traditional Chinese culture: benevolence, wisdom, courage, happiness and elegance, with strong Chinese cultural color. At the same time, the existing research in recent years focuses on different types of tourism, such as rural tourism, waterfront tourism, ancient town tourism, event tourism and so on.

As for the research object, studies have gradually realized the different roles of different themes in shaping destination brand personality, and divided brand personality into projected brand personality and perceived brand personality from the perspective of 
subjects. The difference between the two is also studied [9].

Most existing researches have realized the significance and role of brand personality in destination brand, and tried to explore the approach that destination tourists can perceive and make positive feedback from the perspective of brand personality. However, the booming growth of new media in the era of mobile Internet determines that the research on the exploration, transmission and marketing of the destination brand personality at the practical level require further development.

\section{THE DILEMMA OF BRAND PERSONALITY CREATION IN PRACTICE}

\section{A. Ignoring the value of brand personality, and lacking of destination resources integration}

External challenges including serious homogenization, upgrading of tourists' spiritual needs and different new media marketing still exist. Many destination brand construction is still limited to marketing such as propaganda slogans, text and pictures, video playing, etc., and has not explored its own resource, integrated and refined brand assets, unable to fundamentally create spiritual core different from other destinations. As for the integration of destination resources, destination brand elements are disordered and scattered, and the extraction and refinement of cultural core, spiritual expression and consciousness appeal are not realized. In terms of brand marketing, many destination managers have not yet found positioning and promotion point suitable for the destination brand personality.

In short, brand personality has not obtained due attention from destination managers, and its application and operation still encounter resistance in practice. For urban destinations, in addition to certain type of tourism, factors including city image, residents' style, history and culture, policy and economic development have posed difficulties and tests to the creation of brand personality in practice. A framework that defines destination brand personality and is not limited to a certain conceptual scope also puts forward higher requirements for the integration ability and marketing ability of destination managers.

\section{B. New media platform has not been fully utilized in destination marketing}

The deep integration of Internet and traditional industry has brought great changes to traditional marketing. As mobile Internet picks up, all new media platforms, such as weibo, WeChat official accounts and live streaming platforms, have not only become bridges between producers and consumers, but also enhanced the communication and emotional connection between consumers and potential consumers. Brand communication and transmission are characterized by convenience, rapidity, clarity and emotion. However, there are still some problems in destination marketing, such as single marketing channel, low quality of publicity content and unclear target group.

In terms of marketing channels, destinations gradually began to use weibo and WeChat official accounts in addition to official tourism websites for marketing. However, issues as relatively narrow marketing channels, lack of platform maintenance or blind pursuit for novelty emerge one after another. In terms of publicity content, some of the language is rigid and boring, and the publicity form is old-fashioned. Some of it is limited to policy making and news report, and the brand personality is not obvious. As for target group, the destination fails to make in-depth understanding and emotional communication of tourists, thus the positioning of destination audience is unclear, which increases the difficulty in cultivating tourists' loyalty.

\section{Tourism brand marketing has not yet met the demands of tourists}

The demand of tourists tends to be complicated, diversified, experienced and individualized. Compared with popular scenic spots, tourists pay more attention to the emotional experience needs during the tour. It has become an important means for many tourist destinations to excavate the factors that fit the tourists' deep emotions. Unique and attractive destination brand personality can enhance the image of the destination, thus influencing the choice of tourists. A successful brand personality can differentiate itself effectively from other competitors, increase brand equity and cultivate loyal customer relationships [10].

The destination manager no longer dominate of brand marketing in cultivating brand personality, nor solely determine the destination image. Based on the relevant classification criteria of destination image, destination brand personality can be divided into projected brand personality and perceived brand personality [9]. The former refers to the ideal brand personality created by the destination through various branding activities, while the latter refers to the destination brand personality actually perceived by tourists. If the destination brand personality does not fit well with the needs of tourists, the gap between the two is too large, the brand creation will be easily out of control.

\section{Unclear destination brand evaluation index and evaluation mechanism}

Brand marketing is not accomplished overnight, and it is impossible to achieve marketing objectives simply by "slogans and propaganda". The destination manager 
needs to construct the brand marketing mechanism and evaluate the process according to destination development goals and specific evaluation indexes. However, the marketing with unclear evaluation indexes and imperfect evaluation mechanism leads to various marketing scenes with vague goals, scattered forces and few audiences, with unsatisfactory effects. The sea changes in the evaluation subjects, evaluation standards, evaluation methods and other contents of destination marketing under new media make the destination evaluation full of challenges and difficulties. The establishment of targeted brand marketing mechanism based on development direction of destinations remains to be further explored.

\section{MANAGEMENT RECOMMENDATIONS}

\section{A. Excavating the spiritual core of destination and cultivating the individuality of local brand}

The construction of unique destination brand personality is critical in solving the problem of product homogeneity. The self-expression of the brand lies in the integration and refinement of the cultural resources and spiritual core of the destination. In brand marketing, the integration of cultural resources in destination is based on its deep understanding and keen perception of potential tourists, which requires all stakeholders to participate in the creation of destination brand personality. Destination managers should coordinate comprehensively, make clear responsibilities, integrate destination tourism resources, and deeply explore the core of cultural spirit to cultivate destination brand personality.

\section{B. Making full use of new media for destination brand marketing}

In May 2020, Tik Tok, a live streaming platform, launched "Cloud Tourism Bureau" to interact with potential tourists from an official perspective and sell tickets. Such marketing mode of "tourism plus live streaming" is a new attempt to employ new media for destination brand marketing. The new media provides a communication channel for tourists and threedimensional information. New media, with its interconnectivity and timeliness, breaks the restrictions of time and region, enabling tourists to release information, search for and feedback information anytime and anywhere. Potential tourists prefer the "experience talk" from tourists who had relevant experience and make instant consumption at the same time. Destinations can utilize new media social platforms, such as live broadcasting platform, WeChat official accounts, etc., for marketing. The destination cultural value can be spread on the new platform, and the existing brand marketing effect can be evaluated to maximize the brand marketing effect.

\section{Building destination brand personality that meets the needs of tourists}

Destination managers should focus on the change of tourists' say and the upgrade of tourists' demands against the background of mobile Internet. The reason why consumers choose a given brand often lies in their "similar" or "complementary" personalities. Therefore, it is of great significance to find a brand personality that fits consumers' personalities. Destination managers should pay attention to different new media social platforms and re-evaluate their existing brand marketing effects. The next step is to create appropriate brand personality characteristics for brand positioning according to tourists' needs.

\section{Constructing the evaluation index system of brand personality marketing}

In the new era, the changes of tourism, marketing methods and destinations should be paid attention to. Tourism destination marketing methods, and destination brand marketing effect evaluation should be given due attention to build scientific brand marketing evaluation index system. Therefore, the brand marketing of tourism destination can be carried out scientifically, the transformation and upgrading of tourism products based on the new theoretical perspective can be promoted, and the new thinking of marketing evaluation in the new era is proposed accordingly.

\section{CONCLUSION}

In the new era with booming mobile Internet, new media marketing with wide radiation scope, great influence and strong interaction has become new front for tourism destination brand marketing. The changing demands and more say of tourists have posed new challenges for destination branding. By introducing brand personality, this paper analyzes the existing problems and difficulties in the creation of tourism destination brand personality: ignoring value of brand personality, shorting of destination resource integration, underutilized new media platforms in destination marketing, mismatch between tourism brand marketing and tourists' demands, as well as vague destination brand evaluation index and evaluation mechanism. Corresponding solutions are proposed as follows: excavating the spiritual core of the destination, cultivating the local brand personality, utilizing new media for destination brand marketing, building destination brand personality that meets the needs of tourists, and proposing evaluation index system of brand personality marketing. The above is helpful for the destination to promote transformation and upgrading based on brand personality and conduct scientific brand marketing activities. 


\section{References}

[1] Lv Xingyang, Xu Hong, Lin Shuang. Brand Hijack: The Alienated Evolution Process of Destination Image [J]. Tourism Tribune, 2014, 29(6): 67-75. (in Chinese)

[2] Lynn A J. Dimensions of Brand Personality [J]. Ssrn Electronic Journal, 1997.

[3] Usakli A, Baloglu S. Brand Personality of Tourist Destinations: An Application of Self-congruity Theory [J]. Tourism Management, 2011, 32(1):p.114-127.

[4] Bai Kai, Hu Xianyang. Tourism Destination Brand Personality: Theoretical Sources and Relationships [J]. Tourism Tribune, 2013, 28(4): 35-47. (in Chinese)

[5] Henderson, Joan C. Selling Places: The New Asia-Singapore Brand [J]. Journal of Tourism Studies, 2000, 11(1).

[6] Hosany S, Ekinci Y, Uysal M. Destination Image and Destination Personality: An Application of Branding Theories to Tourism Places [J]. Journal of Business Research, 2006, 59(5):638-642.

[7] Gao Jing, Jiao Yongbing. Differentiating Brand Positioning of Tourism Destinations: A Brand Personality Perspective [J]. Tourism Tribune, 2014, 29(3): 49-57. (in Chinese)

[8] Huang Shengbing, $\mathrm{Lu}$ Taihong. Dimensions of Brand Personality in China [J]. Nankai Business Review, 2003(01): 49. (in Chinese)

[9] Kim S, Lehto XY. Projected and Perceived Destination Brand Personalities: The Case of South Korea [J]. Journal of Travel Research. 2013;52(1):117-30.

[10] Ye Yanfang. A Study on the Relationship of Tourist Destination Brand Personality, Tourist Self-concept and Tourist Behavior Intension [D]. South China University of Technology, 2012. (in Chinese) 